\title{
REDES DE INFORMAÇÃO CIENTÍFICA E OS DESAFIOS PARA POPULARIZAÇÃO DA CIÊNCIA: ESTUDO DE CASO NA REDE SIEO - SISTEMA DE INFORMAÇÃO ESPECIALIZADO NA ÁREA DE ODONTOLOGIA
}

\section{REDES DE INFORMACIÓN CIENTÍFICA Y LOS DESAFÍOS DE LA POPULARIZACIÓN DE LA CIENCIA: UN ESTUDIO DE CASO EN LA RED SIEO - SISTEMA DE INFORMACIÓN ESPECIALIZADA EN EL ÁREA DE LA ODONTOLOGÍA.}

Lúcia Maria S. V. Costa Ramos - Iveronica28@gmail.com Doutoranda em Ciência da Informação pela Universidade de São Paulo (USP). Diretora Técnica do Serviço de Documentação Odontológica da Faculdade de

Odontologia da USP.

Asa Fujino - asa.fujino@gmail.com Doutora em Ciências da Comunicação pela Universidade de São Paulo. Docente do Departamento de Biblioteconomia e Documentação da USP.

\section{RESUMO}

Introdução: Os estudos contemporâneos sobre ciência têm evidenciado as profundas raízes sociais que o conhecimento e as práticas científicas possuem. Paralelamente, surge a consciência de que a popularização da ciência é fundamental para que o conhecimento científico possa se tornar componente essencial da cultura dos cidadãos em geral, possibilitando a integração cultural, social e econômica.

Objetivo: Estudar o potencial de atuação de redes cooperativas de informação na popularização da ciência, considerando os desafios organizacionais (infraestrutura, recursos humanos, comprometimento da alta administração) que uma Rede como a SIEO teria para atuar nesse novo contexto.

Metodologia: Trata-se de um estudo exploratório pautado no modelo de rede colaborativa de informação que utiliza a pesquisa qualitativa como marco de orientação para a pesquisa empírica e alia a pesquisa documental com o estudo de caso. 
Resultados: Mostram que, embora a Rede esteja preparada do ponto de vista da estrutura organizacional e operacional e da qualidade dos seus acervos, a carência de recursos financeiros e de equipe qualificada para geração de materiais específicos para divulgação científica e ações em prol da popularização da ciência inibe as possibilidades de aproveitamento imediato deste potencial. Também mostra que a cultura organizacional é ainda pouco flexível à interação com segmentos mais populares da sociedade.

Conclusões: Conclui-se que tal fato demanda ações de mediação no atendimento a este usuário, seja por linguagens de recuperação da informação que permitam estabelecer equivalências entre a língua de especialidade e a linguagem comum, seja por formas mais adequadas de representação da informação científica, visando à divulgação científica.

Palavras-chave: Rede de Informação Científica. Planejamento e gestão de Serviços. Popularização da Ciência. Divulgação Científica. Estrutura Organizacional.

\section{INTRODUÇÃO}

Observamos que o século XXI exibe avanços científicos sem precedentes, com inúmeros benefícios para a sociedade, mas percebemos também que grande parte destes benefícios está distribuída de maneira visivelmente desigual.

Neste contexto, não basta apenas à busca de diálogo entre as diversas áreas do conhecimento científico, é preciso que ocorra uma mudança estratégica das organizações provocando alterações na sua identidade estrutural e operacional, pondo em questão seus paradigmas tradicionais (BENJAMIN; LEVINSON, 1993).

O entendimento da mudança estratégica exige uma construção multidimensional e multifacetada e parte da compreensão de uma estrutura integrada e multidisciplinar. Assim, os velhos padrões de uma organização rígida, lenta, sem criatividade e insensível às necessidades atuais, devem ceder lugar às estruturas organizacionais flexíveis, enxutas, inovadoras, competitivas e eficientes. No que se refere às organizações da sociedade da informação, espera-se que estejam abertas a novas formas de disseminação da informação que atendam não só a comunidade acadêmica, mas também ao público leigo.

Em torno dessas mudanças de padrões têm surgido várias práticas e discursos sobre uma pretensa e necessária popularização da ciência e da tecnologia e, embora a questão não seja nova, o acelerado avanço científico e tecnológico tem trazido esse debate de volta, com maior freqüência. As iniciativas em torno do problema nem sempre são claras e em muitos casos apenas contribuem para manutenção ou crescimento da grande separação entre conhecimento científico e tecnológico. No mundo moderno consolidou-se a visão de um conhecimento 
científico e tecnológico isolado da sociedade e que, justamente por isso, adquiriu as características de ser imune a questionamentos e distante das demandas da população geral (LÉVY-LEBLOND, 1992, 2006; MYERS, 2003; NIETO, 2002). Essa abordagem leva necessariamente a considerar a ciência como um corpo de conhecimento que se inicia e termina nos laboratórios de pesquisa, e não como uma perspectiva dinâmica, humana, em contexto social, cultural, político e econômico.

Neste sentido, a divulgação da Ciência e Tecnologia (C\&T) tem sido comumente compreendida como um processo de simplificação, que busca traduzir o conhecimento científico dos especialistas para os não especialistas (MYERS, 2003) e que acontece como uma atividade posterior e diferenciada da produção de conhecimento. Nessa visão, assume-se ainda que: a) os cientistas e as instituições científicas são autoridades no que se refere à ciência, b) o público se encontra em um estado de ignorância sobre assuntos de ciência e tecnologia, c) o conhecimento é transmitido em uma única via dos cientistas para a sociedade e d) o processo de transmissão implica que a informação seja simplificada e distorcida.

Entretanto, os estudos contemporâneos sobre ciência têm evidenciado as profundas raízes sociais que o conhecimento e as práticas científicas possuem. Paralelamente, surge a consciência de que a popularização da ciência é fundamental para que o conhecimento científico possa se tornar componente essencial da cultura dos cidadãos em geral, possibilitando a integração cultural, social e econômica. Ações de divulgação científica passam a ser vistas sob perspectiva pedagógica, ganhando relevância na melhoria da qualidade da formação educacional para a cidadania e da consciência social coletiva. As alternativas e mecanismos de divulgação científica se tornam estratégicas no processo de desenvolvimento social.

Assim sendo, o referencial teórico utilizado para operacionalizar a presente pesquisa pautou-se no modelo de rede colaborativa de informação para refletir sobre os potenciais desafios gerenciais que um Sistema de Informação Científica, configurado em Rede, terá que enfrentar para atuar na popularização da ciência, assegurando condições adequadas de apropriação da informação por usuários não científicos. Parte do estudo deste tipo de organização para analisar o seu potencial de contribuição para a divulgação da ciência e da tecnologia no processo de construção de um ambiente de equidade social e econômica. Optou-se pela Rede SIEO, como objeto do estudo de caso, pelo fato de ser uma rede multilateral que 
Lúcia Maria S. V. Costa Ramos; Asa Fujino

Redes de informação científica e os desafios para popularização da ciência: estudo de caso na rede Sieo - sistema de informação especializado na área de odontologia

busca a integração educativa, científica, tecnológica e cultural das 17 bibliotecas que a compõem e que se localizam de norte a sul do país. Partiu-se do pressuposto que os atores envolvidos nesta Rede, podem, além do apoio ao desenvolvimento científico, atuar como um dos pilares da Política Pública de Saúde Bucal, contribuindo com a Educação e Informação das comunidades populares via Divulgação Científica.

\section{OBJETIVOS}

Estudar o potencial de atuação de redes cooperativas de informação na popularização da ciência, considerando os desafios organizacionais (infraestrutura, recursos humanos, comprometimento da alta administração) que uma Rede como a SIEO teria para atuar nesse novo contexto.

\section{METODOLOGIA}

\subsection{Considerações conceituais}

O ponto de convergência deste artigo são as relações entre sociedade da informação, universidade pública e popularização da ciência que permeiam a área de saúde e, especificamente a odontologia.

Levando-se em consideração o crescimento da área de divulgação científica no país, propomos inicialmente compreender os pressupostos que orientam o discurso de popularização da ciência e tecnologia e a forma que as ações políticas empreendidas assumem na comunicação pública da ciência.

Como parte do processo, esperamos entender as relações que são estabelecidas entre saúde bucal, rede de informações e popularização da ciência.

Trata-se de um estudo exploratório que utiliza a pesquisa qualitativa como marco de orientação para a pesquisa empírica e alia a pesquisa documental com o estudo de caso.

Em relação ao caráter exploratório da pesquisa Gil (1988) considera que suas principais características são desenvolver, esclarecer e modificar conceitos e idéias com vistas à formulação de problemas mais precisos ou hipóteses pesquisáveis 
Lúcia Maria S. V. Costa Ramos; Asa Fujino

Redes de informação científica e os desafios para popularização da ciência: estudo de caso na rede Sieo - sistema de informação especializado na área de odontologia

para estudos posteriores. Este tipo de pesquisa é desenvolvido com o objetivo de proporcionar visão geral de tipo aproximativo, sobre determinado fato.

Complementarmente, no Estudo de Caso a pergunta de pesquisa deve estar focada em "como" e "por que", questões que levam à análise da evolução de um fenômeno ao longo do tempo e para as quais a contagem de incidências, por exemplo, pode não trazer respostas e do ponto de vista temporal, permite que o fenômeno seja estudado com base em situações contemporâneas, que estejam acontecendo, ou em situações passadas, que já ocorreram e que sejam importantes para a compreensão das questões de pesquisa colocadas.

É o caso específico deste estudo, onde a compreensão da dimensão tácita presente nas ações de divulgação científica da Rede SIEO é essencial para entender a cultura organizacional que permeia as instituições que compõem a estrutura em rede, para além dos aspectos formais.

No que se refere aos procedimentos adotados para o estudo do caso selecionado, optou-se pelo método histórico que permitiu compreender a conformação da rede ao longo desta década e uma análise diacrônica das políticas e decisões de cada instituição integrante do SIEO, bem como do aprendizado coletivo decorrente da experiência de trabalho em rede.

Considerando que a intenção do artigo foi a de estudar o potencial de contribuição da rede SIEO para ações de popularização da ciência, a parte empírica buscou investigar as condições objetivas (interesse, experiência e infraestura) das instituições participantes para atividades de popularização da ciência. Optou-se pela análise de relatórios e outros documentos produzidos pela rede, para observar a predominância de valores eventualmente explícitos na cultura organizacional das instituições integrantes da rede que influíram nas decisões que levaram (ou não) as instituições a ações reconhecidas como de divulgação científica ou outras que pudessem ser consideradas motivadas por interesses de popularização da ciência.

Para a análise dos documentos oficiais que tratam da Rede e dos contratos de parceria de seus integrantes foi enviado aos 17 diretores de bibliotecas das instituições integrantes da rede um questionário semi estruturado acompanhado de carta explicando o objetivo da pesquisa e solicitando participação, além de um termo de consentimento que deveria ser devolvido assinado pelo respondente composto de 16 questões, das quais 3 abertas, subdivididas em 3 partes: parte I: dados de identificação do respondente; parte II: informações sobre a estrutura e cultura 
organizacional; e parte III: informações sobre experiência ou intenção institucional de desenvolver ações voltadas à popularização da ciência.

O questionário e demais anexos foram encaminhados por endereço eletrônico, e a coleta dos dados abarcou o período de julho a agosto de 2010.

Documentos sobre a rede ou seus integrantes foram obtidos nos endereços eletrônicos das instituições armazenados no endereço eletrônico do Centro Coordenador da Rede SIEO Disponível em: http://www.fo.usp.br/sdo/sieo/index.html, através deste endereço temos acesso às informações dos integrantes da rede.

Para assegurar não identificação pública do respondente ou individualização de dados institucionais, cada instituição recebeu um código alfanumérico que foi utilizado para tabulação e análise dos dados. Deste modo, manteve-se o sigilo sobre as fontes individuais, sem comprometimento da veracidade dos dados apresentados no relatório do estudo de caso

\section{ESTRUTURA ORGANIZACIONAL EM REDE}

Conceituar estrutura organizacional em rede não é tarefa fácil. Observa-se que não existe uma regra uniforme na terminologia empregada, encontrando-se denominações como: organização em rede, organização rede, formas de redes organizacionais, redes organizacionais, redes inter-empresas, network, networking, organizações sem fronteiras, teias, colegiado, entre outras (OLIVARES, 2003).

A estrutura organizacional do século XXI poderá tomar a forma de rede, visto que a rede está emergindo como forma principal de organização na era da informação (BARNATT, 1996). Nohria e Eccles (1992) argumentam que o desempenho de uma rede depende de dois fatores fundamentais: a conectividade, isto é, a capacidade de a estrutura organizacional facilitar a comunicação sem ruídos entre os indivíduos, e a coerência, o compartilhamento de interesses entre os participantes da rede. Kataoka (1999) complementa tais argumentos, observando que essas formas organizacionais do tipo de rede são importantes tanto na perspectiva profissional como na acadêmica.

No conceito de Ghoshal e Bartlett (2000, p. 105-106) e Cohen (2000), a estrutura organizacional em rede se ergue com base em atividades distribuídas e especializadas e um conjunto de relacionamentos mais fundamentados na 
Lúcia Maria S. V. Costa Ramos; Asa Fujino

Redes de informação científica e os desafios para popularização da ciência: estudo de caso na rede Sieo - sistema de informação especializado na área de odontologia

interdependência do que na dependência ou independência, bem como consistem em interações ou relacionamentos entre colaboradores interdependentes que operam simultaneamente para o alcance de um objetivo.

A comunicação é fator de suma importância em uma estrutura organizacional em rede, pois se caracteriza por se integrar em todos os níveis hierárquicos, baseada em tecnologias de comunicação e informação (internet e extranet), o que permite atuação mais ágil e adequada de acordo com as necessidades do momento (PECI, 1998, p. 6).

No caso das redes cooperativas de informação científica, particularmente a SIEO, é possível afirmar que a sua implementação só foi possível em função do desenvolvimento da Internet, uma vez que atua com uma estrutura organizacional descentralizada, que garante a autonomia decisória dos seus integrantes, daí a necessidade de consultá-los sobre o interesse e particularidades internas para ações não previstas quando da constituição da rede.

\section{REDES COLABORATIVAS E A INTER-RELAÇÃO ORGANIZACIONAL DOS SISTEMAS DE INFORMAÇÃO}

Na sociedade inter-relacionada, a fonte primária de criação de valor mudou a ênfase da produtividade para os relacionamentos, e a capacidade de colaborar precisa se tornar uma competência-chave para a organização (CASTELLS, 1998). Pode-se dizer também que a mais importante competência é a habilidade para integrar as competências dos parceiros. Os desafios que as organizações enfrentam requerem cada vez mais o esforço colaborativo e a efetiva ação coordenada de várias organizações, incluindo governo, setor privado e terceiro setor (CARVALHO; RAMOS, 2009).

A decisão de implementar sistemas inter-relacionados, na esfera das universidades públicas ou em qualquer tipo de organização, significa uma quebra de paradigma e a adoção do modelo colaborativo implica atuação com outros limites e novas regras.

Fujino e Stal (2004) entendem que um sistema de informação científica está diretamente conectado ao desenvolvimento científico-tecnológico e reflete as relações entre Estado, Ciência e Sociedade em determinado contexto espaço temporal e, conseqüentemente, cria condições para estabelecer uma política de 
informação e diretrizes que orientarão as ações e os meios destinados à formação de memórias científicas e disseminação de informação.

As motivações para o envolvimento de uma estrutura organizacional no planejamento de sistemas inter-relacionados podem ser resumidas em quatro grupos principais:

a) compartilhamento de informações;

b) aumento de produtividade;

c) determinação superior, legal ou normativa;

d) incremento do relacionamento com os usuários.

Neste contexto, podemos classificar os sistemas inter-relacionados como uma infraestrutura de informação global descrita como uma rede de rede locais, nacionais e regionais e considerada como produto da convergência tecnológica, que tornaria possível o compartilhamento da informação, da interconexão, da comunicação e da constituição de um mercado global de informação, visto graças ao desenvolvimento maciço das tecnologias de informação e o complexo panorama de redes que se instaurou em âmbito global (CARVALHO; RAMOS, 2009).

\section{FORMAÇÃO DA REDE DE ODONTOLOGIA - REDE SIEO}

As organizações atuais têm seu desenvolvimento atrelado à forma como organizam, tratam, processam e representam a informação e é necessário estabelecer mecanismos eficientes para tratá-la adequadamente. A forma como ocorrerá a organização da informação poderá gerar resultados que garantam a sobrevivência destes organismos em sociedade.

Com o objetivo de atender às demandas sociais surgiu $O$ projeto "Implementação de rede de informação na área odontológica", apresentado à W. K. Kellogg Foundation, nos Estados Unidos, em 1990 e aprovado em 1991, em parceria com a BIREME (Centro Latino-Americano e do Caribe de Informação em Ciências da Saúde), tendo como preocupação básica tratar o fenômeno informação enquanto problemática social. Em 1991, através de Termo Aditivo ao Convênio BIREME/USP, firmado em 1990, o SDO tornou-se o "Centro Coordenador Nacional de Informação em Ciências da Saúde Oral”. Deste convênio originou-se o projeto 
Lúcia Maria S. V. Costa Ramos; Asa Fujino

Redes de informação científica e os desafios para popularização da ciência: estudo de caso na rede Sieo - sistema de informação especializado na área de odontologia

apresentado à W. K. Kellogg Foundation, no qual a Universidade de São Paulo foi representada pela Faculdade de Odontologia e o seu Serviço de Documentação Odontológica (KRZYZANOWSKI, 1990).

Segundo Carvalho e Ramos (2009), a partir da compreensão da importância da difusão da informação na área odontológica e da abrangência que a construção de uma Rede de informação especializada teria no contexto nacional e internacional, promoveram-se esforços no sentido de recuperar a informação, em seus diversos níveis, para todo o território brasileiro visando proporcionar o acesso às fontes de informação em odontologia e a popularização da ciência em área que não tem sido priorizada nas políticas públicas de saúde Ela tem como missão oferecer mecanismos para atender, de forma sistêmica, as necessidades informacionais da comunidade odontológica nacional e internacional e opera com base nos princípios dos Programas de Qualidade e da Administração Estratégica. Conta, atualmente, com o apoio de dezessete bibliotecas nacionais (centros cooperantes) da área de odontologia (Figura 1), distribuídas em várias regiões do Brasil:

Figura 1 - Centros Cooperantes atuais do SIEO

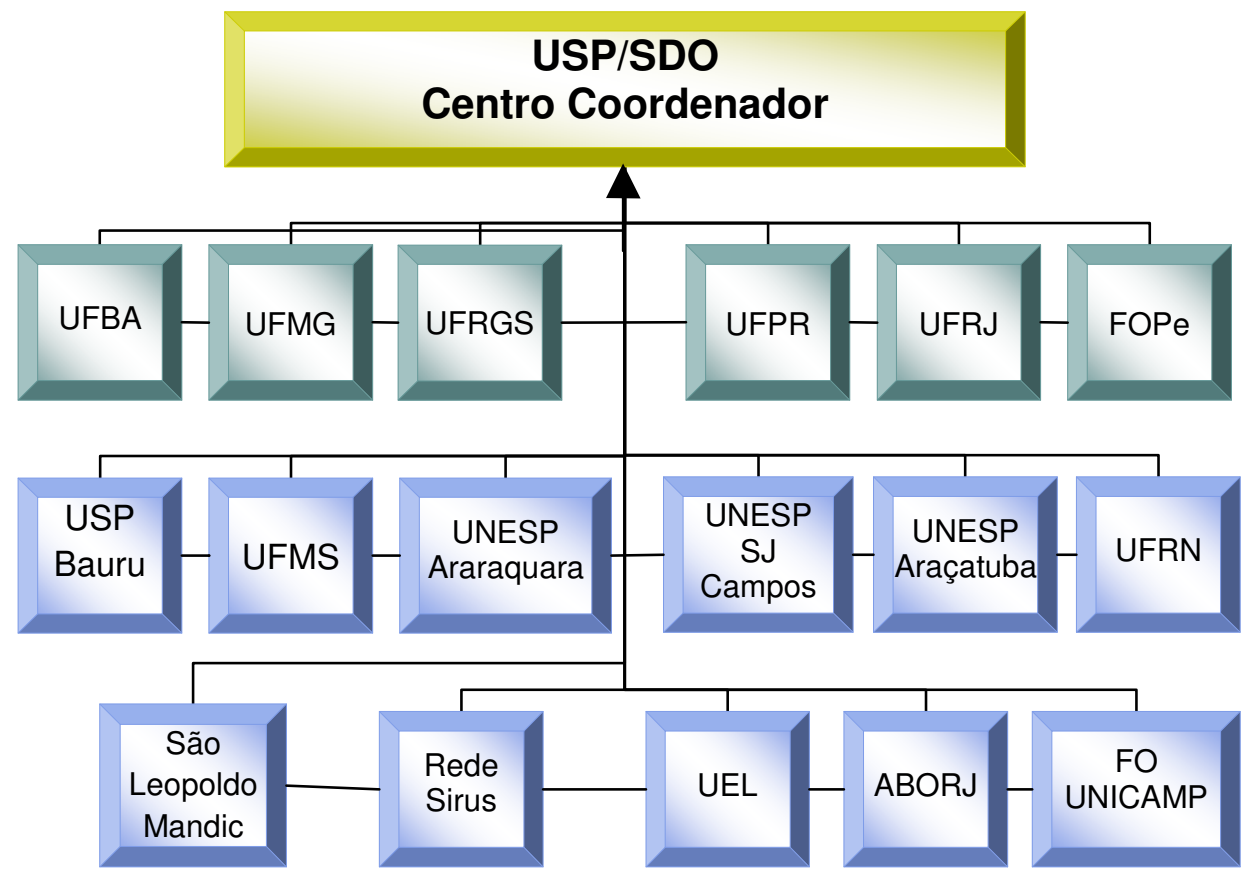

Fonte: Carvalho e Ramos (2009, p. 389) 


\section{REDES DE INFORMAÇÃO CIENTíFICA E A POPULARIZAÇÃO DA CIÊNCIA}

As primeiras iniciativas de divulgar dados de pesquisas científicas são registradas em livros, conferências e em demonstrações de experimentos para um público restrito. Segundo Macedo (2002), a divulgação para um público mais amplo tem início no século XVI, com os primeiros periódicos científicos.

Por outro lado, as publicações científicas estão cada vez mais específicas, de tal forma que pesquisadores de uma determinada área apresentam dificuldades para compreender conhecimentos que são de áreas diferentes a da sua atuação. Nesse sentido, Guará (2002, p. 85-86) observa que "o acesso ao conhecimento científico não pode ser o crivo de ampliação da exclusão social e da concentração de poder, que beneficia apenas os que dispõem de meios para atualizar-se". As inovações tecnológicas e os grandes avanços da ciência fazem parte do nosso cotidiano e cresce a preocupação com alternativas relativas à popularização da Ciência.

Nesse sentido, o governo brasileiro, através do Ministério da Ciência e Tecnologia (MCT), em 2009 estabeleceu um programa com 24 áreas de atuação, sendo uma delas a de inclusão social, a qual o MCT articulou de forma oficial um discurso de Difusão e Popularização da C\&T, o que levou à legitimação e institucionalização da área, no âmbito político. O processo de crescimento da área de divulgação científica do país ocorre paralelamente a uma política de estímulo do próprio governo, visando articular iniciativas existentes e criar, ao mesmo tempo, condições propícias para o surgimento de novos programas e projetos.

O referido programa propôs focalizar aspectos como divulgação do conhecimento científico; difusão da produção nacional em C\&T; alfabetização científica em espaços não formais de ensino, apoio e fomento e eventos e olimpíadas de C\&T; sistemas de informação; centros e laboratórios para o ensino de ciências; bibliotecas digitais; experiências de ensino de C\&T e apoio a difusão de tecnologias (BRASIL, 2003a). Para isso considerou-se necessária a articulação de ações com órgãos vinculados com o Fundo Nacional de Desenvolvimento Científico e Tecnológico (FNDCT), a Secretaria de Inclusão Social (SECIS), o Instituto Brasileiro de Informação em Ciência e Tecnologia (IBICT), o Museu de Astronomia e Ciências Afins (MAST) e o Conselho Nacional de Desenvolvimento Científico e Tecnológico (CNPq). 
Documentos publicados por governos anteriores deixaram manifesto um interesse por abordar as relações entre a ciência e a sociedade e serviram de base para elaboração de publicações do governo em 2002, que no Livro Branco: Ciência, Tecnologia e Inovação (BRASIL, 2002), resultado da II Conferência Nacional de CT\&I realizada em setembro de 2001, aproxima o debate sobre ciência e tecnologia nacional com a comunidade acadêmica, ao setor produtivo e a cidadania geral.

É interessante destacar, neste ponto, que os anais da II Conferência Nacional de CTI, o Livro Branco e o Plano Plurianual serviram de base para a formulação de um Plano Estratégico 2004-2007 que levaria, como indicado no próprio documento (BRASIL, 2003b, p. 3), à implementação de ações e programas em três eixos fundamentais, atualmente em desenvolvimento, e que ajudariam a consolidar e fortalecer o Sistema Nacional de Ciência e Tecnologia: Política industrial, tecnológicas e de comércio exterior; Objetivos estratégicos nacionais e Inclusão social.

O eixo Inclusão social, propunha o programa Difusão e Popularização da Ciência, e envolvia, entre outras atividades, a implantação e modernização de 100 Centros Vocacionais Tecnológicos em diferentes estados do país e a realização de eventos de popularização e difusão da C\&T.

Em 2003, como fruto das decisões do novo governo e do empenho de entidades da sociedade civil, foi criada a Secretaria de Ciência, Tecnologia e Inclusão Social (SECIS), órgão específico do MCT.

Para viabilizar as suas funções, a SECIS deu origem ao Departamento de Ações Regionais para a Inclusão Social e ao Departamento de Popularização e Difusão de Ciência e Tecnologia (DEPDI), a este último foram associadas atribuições específicas, como: formular políticas e implementar programas de popularização da C\&T; colaborar com a melhoria do ensino de ciências, em parceria com o MEC e com as secretarias estaduais de educação; apoiar centros e museus de ciências e apoiar eventos de divulgação científica (BRASIL, 2003b).

Essas atribuições nos revelam compromissos assumidos com a popularização da C\&T, a divulgação científica e o ensino de ciências no país, com impacto nacional, como a Semana Nacional de C\&T e o programa Ciência Móvel ao qual aderem, a cada ano, novas instituições de pesquisa e de ensino de diversos municípios do país. 
Lúcia Maria S. V. Costa Ramos; Asa Fujino

Redes de informação científica e os desafios para popularização da ciência: estudo de caso na rede Sieo - sistema de informação especializado na área de odontologia

Além desses programas, Moreira (2006) apontava a promoção e apoio de diversas ações, algumas delas especificamente voltadas para a melhoria do ensino de ciências, como olimpíadas e feiras de ciências, a produção de material didático e a criação e aprimoramento de espaços para a experimentação, além de outras voltadas para a divulgação científica, como eventos, congressos nacionais e internacionais, programas de TV e produção de materiais de divulgação, por parte do DEPDI.

No que se refere à divulgação científica, Moreira e Massarani (2002, p. 56) referem-se:

[...] ao crescimento de centros e museus de ciências e de eventos de divulgação científica, que apesar dos esforços realizados, se mostra ainda com um quadro frágil e limitado; a ausência de políticas definidas na área, que promovam a articulação de diferentes atores sociais (universidades, institutos de pesquisa, organismos públicos); a cobertura deficiente dos meios de comunicação, especialmente no que se refere à interface ciência-cultura; a predominância do modelo de déficit, nos processos de divulgação científica e a falta de inclusão social de grupos marginalizados.

O DEPDI apresentou também dez diretrizes que poderiam orientar a política de popularização da C\&T

Contribuir para: aumento da apreciação coletiva da importância da C\&T no mundo moderno; conhecimento científico-tecnológico geral mais aprofundado; estímulo a curiosidade, criatividade e inovação; entendimento por parte do cidadão do funcionamento de C\&T; diminuição da "exclusão do conhecimento"; estabelecimento de uma cultura científica na sociedade. Promover a melhoria a uma maior atualização/modernização do ensino das ciências em todos os níveis de ensino. Ênfase nas ações e atividades que valorizem e estimulem a criatividade, a experimentação e a interdisciplinaridade. Buscar uma maior presença da C\&T brasileira nos meios de comunicação. Aumentar a auto-estima dos brasileiros neste domínio com uma justa apreciação das contribuições de indivíduos, instituições e empresas nacionais. Estimular o uso e a difusão da C\&T em ações de inclusão social e redução das desigualdades. Promover ações que estimulem o aumento da participação na C\&T de jovens de todos os seguimentos (como exemplo mulheres e jovens de extratos sociais pobres). Estimular que as atividades de PCT não se restrinjam à áreas de ciências exatas e naturais, mas que incorporem também ciências sociais e humanas. Promover interação entre ciência, a cultura e a arte, com uma maior aproximação da C\&T com o cotidiano das pessoas e valorizando os aspectos culturais e humanísticos da ciência. Respeito e reconhecimento de conhecimentos populares e tradicionais. Proteção ao meio ambiente

Inf. Inf., Londrina, v. 18, n.1, p. 33 - 58, jan./abr. 2013. http:www.uel.br/revistas/informacao/ 
e desenvolvimento sustentável. Intensa parceria em atividades de popularização da C\&T com governos estaduais e municipais, outras áreas do governo federal, legislativo, entidades de C\&T, Terceiro Setor, empresas estatais e privadas, universidades e instituições de pesquisa. Estimular e promover maior participação popular nas questões gerais de C\&T.

O seguimento de popularização da C\&T envolve a valorização do trabalho em extensão, a formação de comunidades da ciência, o desenvolvimento do programa Ciência Móvel, a promoção de pesquisas de percepção pública da ciência e da tecnologia, a edição de livros de divulgação da C\&T, o estímulo a atividades de turismo científico e ações conjuntas aos espaços legislativos (BRASIL, 2003b).

A linha relacionada com mídias considera, entre outros, ações de parcerias com emissoras de TV e rádios estatais e comunitárias, programas de estágio para jornalistas e o desenvolvimento de campanhas de inclusão social.

A linha de educação científica envolve a criação de câmaras técnicas, o estabelecimento de parcerias com o Ministério da Educação e com as Secretarias de Educação, o estímulo a programas de formação de professores, a promoção de eventos como feiras e olimpíadas, a produção de material didático e a criação de instâncias entre universidades e escolas.

Em 2004, o CNPq incorporou dentro dos seus comitês o Comitê Temático de Divulgação Científica, destinado a selecionar solicitações nacionais de auxílios para atividades de pesquisa e prática na área de divulgação e popularização da C\&T. No ano seguinte, durante a III Conferência Nacional de CT\&I, que aconteceu em 2005, o Departamento de Popularização e Difusão da C\&T (DEPDI) apresentou o "esboço de uma política pública para a popularização da C\&T no Brasil” e levantou aspectos centrais relacionados ao quadro atual da divulgação científica e da educação científica no país.

Em 2006, o Ministério da Ciência e Tecnologia lançou junto ao CNPq, como parte da Ação Transversal Difusão e Popularização da Ciência e Tecnologia, o Edital MCT/CNPq no 12/2006 (Anexo A) - Seleção Pública de Projetos para Apoio a Projetos de Difusão e Popularização da Ciência e Tecnologia (CONSELHO NACIONAL DE DESENVOLVIVMENTO CIENTÍFICO E TECNOLÓGICO, 2006).

Assim, em 2007, o site do CNPq explicitava atividades a serem desenvolvidas por pesquisadores contemplados com Bolsas de Produtividade em Pesquisa 
Lúcia Maria S. V. Costa Ramos; Asa Fujino

Redes de informação científica e os desafios para popularização da ciência: estudo de caso na rede Sieo - sistema de informação especializado na área de odontologia

associadas às duas áreas prioritárias, a divulgação e popularização da C\&T e o ensino de ciências:

Como atividades-fins de Divulgação Científica e Popularização da Ciência e Tecnologia, compreendem-se a realização de pesquisas sobre Divulgação Científica e Popularização da Ciência e Tecnologia, a formação de recursos humanos nessa área, e/ou a elaboração de materiais destinados ao grande público ou públicos específicos mais abrangentes, veiculados e difundidos pelas diversas mídias e instrumentos disponíveis: jornais da grande imprensa ou jornais locais, revistas não especializadas de circulação ampla, páginas de internet, televisão aberta ou por assinatura, emissoras de rádio, museus e similares, instituições culturais, eventos públicos, exposições, livros, teatro, cinema e outras forma de arte. Como atividades-fins de Ensino de Ciências, compreendem-se a realização de pesquisas sobre o Ensino formal e informal de Ciências, bem como a elaboração e o desenvolvimento de metodologias e de materiais didáticos ou para didáticos destinados a alunos dos vários níveis de ensino, exceto o ensino universitário de carreiras específicas (CONSELHO NACIONAL DE DESENVOLVIMENTO CIENTÍFICO E TECNOLÓGICO, 2007).

Pelo exposto nos é apresentado que as ações de caráter institucional que se iniciaram em 2003, como a criação do DEPDI e do CTDC/CNPq; possibilitaram o desenvolvimento de outras, de grande importância para a área de popularização da C\&T, como o lançamento de editais e a formulação de diretrizes de ação para uma política nacional.

No caso específico da Rede SIEO, procurou-se identificar as relações complexas entre os significados pessoais e sociais, as práticas individuais e culturais da pesquisa em saúde bucal e as formas de divulgação científica em contexto específico caracterizado pela Rede. Este sistema de informação tem um papel importante no âmbito da disseminação da informação científica, por ser uma rede de informação especializada em odontologia integrada com dezessete bibliotecas universitárias de norte a sul do país, com grande potencial para atuação junto aos pesquisadores, mas também junto às comunidades locais. Apesar de a Odontologia ser uma especialidade médica existente há anos, a contribuição das suas pesquisas para a saúde da população é ainda pouco conhecida, não pelo desinteresse das pessoas, mas provavelmente por falta de informação e de divulgação por parte dos próprios profissionais que atuam na área. 


\section{ANÁLISE E INTERPETAÇÃO DOS DADOS}

A análise dos documentos oficiais que tratam da Rede e dos contratos de parceria de seus integrantes foi complementada por um questionário enviado aos 17diretores de bibliotecas das instituições integrantes da rede e teve retorno de 16 respostas $(94,11 \%)$. No entanto, desse total, três entrevistados $(18,75 \%)$ devolveram o questionário em branco, um entrevistado não respondeu ao questionário, o que significa que a amostra analisada é constituída por 13 instituições, correspondente a $81,25 \%$ da população.

Principais resultados:

\section{a) Ações de extensão comunitária}

A pesquisa revelou que onze integrantes da Rede desenvolvem atividades consideradas de extensão à comunidade e elas são prioritariamente desenvolvidas junto às escolas públicas e privadas (aproximadamente $90 \%$ ), creches $(80 \%)$ e postos de saúde ( $80 \%)$. Observou-se também uma atenção aos grupos especiais que aparecem em terceiro lugar com $70 \%$ de atuação. As ações em comunidades de bairro correspondem a 50\%. As Ong's aparecem com pouco mais de $20 \%$ de atenção. Já no item outros, não foram especificadas quais seriam as ações e aparecem com menos de $20 \% \%$. Os locais onde as ações são desenvolvidas reflete as opções da comunidade científica local, mas é importante observar que essas ações ocorrem como transmissão de informações e conhecimentos de uma fonte de saber, sem a adequação necessária para garantir a apropriação do sentido pelo receptor.

\section{b) Formas utilizadas de extensão comunitária}

Para operacionalizar as ações comunitárias foram elencadas várias ações sendo que palestra é o meio mais utilizado pelos respondentes $(80 \%)$, em segundo lugar vêm às apresentações em áudio visuais (pouco mais de $60 \%$ ), seguidas de aulas, cursos/seminários e folhetos/jornais/revistas, TV local e treinamentos programa de rádio. Considerando que as ações são empreendidas pelo público universitário, observou-se que os três primeiros meios mais utilizados decorrem das facilidades locais e institucionais. 
c) Fatores facilitadores para implementação de programas de popularização da ciência

Observou-se que $99 \%$ dos respondentes têm apoio da direção e autonomia da equipe técnica no planejamento e implementação das ações, fatores estes de suma importância para o desenvolvimento das ações. Equipe capacitada aparece com pouco mais de $60 \%$, apontando para fator a ser melhorado para que se atinja satisfatoriamente as ações de extensão comunitária. Quanto à facilidade de parcerias (40\%), este índice demonstra a dificuldade das instituições em conseguir parceiros para ações de extensão comunitária, o que atrelada a Recursos financeiros como fator com o menor índice de facilidade (pouco mais de $20 \%$ ), mostra as maiores deficiências em comum nas instituições públicas. Os itens facilidade de obtenção de informação e infra estrutura adequada se aproximam dos $30 \%$. Este percentual merece maior atenção por parte das instituições e, principalmente, das bibliotecas integrantes da rede SIEO, pois era esperado que tratando-se de instituições integrantes de uma rede de informação científica, o índice relativo à facilidade para obtenção de informação fosse um dos mais elevados. Nesse caso, convém complementar pesquisa para verificar objetivamente as variáveis que influenciaram na avaliação do item.

d) Fatores que dificultam a implementação de programas de popularização da ciência

O fator com maior índice de dificuldade para implementação de programas de extensão comunitária é a ausência ou insuficiência de recursos financeiros $(60 \%)$, em seguida vem dificuldade de parcerias (mais de $40 \%$ ), infra estrutura inadequada (mais de $30 \%$ ), equipe insuficiente ou inexperiente (mais de $20 \%$ ), equipe técnica que não participa da decisão sobre ações de extensão (menos de $10 \%$ ), ausência de apoio da direção e outros não foram pontuados.

\section{e) Participação e importância de atividades de extensão à comunidade} na divulgação do conhecimento científico

A resposta a este item foi vinculada às questões em que os respondentes foram instados a selecionar ações de extensão comunitária praticadas pela instituição. $O$ objetivo era verificar se o respondente reconhecia tais ações como sendo ações voltadas à divulgação científica e não apenas como de assistência 
social. Como opções de resposta foram dadas apenas as alternativas "sim" e "não". Obtivemos $80 \%$ de sim, $10 \%$ de não, e $10 \%$ não aplicáveis. O índice de $20 \%$ que não reconhece tais ações como de divulgação científica é importante, pois aponta para uma aparente separação entre o conceito de extensão universitária e de divulgação do conhecimento. É necessário investigar se há problemas de compreensão dos conceitos ou se, de fato, a relação entre o trabalho, de caráter assistencial ou não, desenvolvido no âmbito da extensão universitária, e a pesquisa científica desenvolvida no âmbito dos programas de graduação e pós-graduação não estão claras.

Tal possibilidade não foi aventada na pesquisa, pois um dos critérios para que as instituições pudessem participar como integrantes da Rede foi justamente a existência de cursos de pós-graduação "stricto sensu".

\section{f) Participação e importância de atividades de popularização da ciência} na área de saúde bucal

Este item tinha como objetivo verificar o conhecimento do respondente sobre se a instituição mantém algum programa de popularização da ciência e compreender o seu posicionamento sobre se considera importante a participação da instituição na área de saúde bucal. Embora todas as instituições da amostra desenvolvam ações compreendidas como de popularização da ciência, há considerável percentual (18\%) que não considera importante que a instituição deva desenvolver ações nesse sentido.

\section{CONSIDERAÇÕES FINAIS}

Na denominada "sociedade do conhecimento" ou "sociedade da informação", a abordagem do tema das redes de informação especializadas pressupõe uma reflexão sobre o caráter político adquirido pelo conhecimento, centrada no caráter público ou privado que engloba sociedade, particularmente no Brasil, no qual tais redes são formadas predominantemente por instituições públicas de ensino e pesquisa, com a atenção voltada essencialmente para o atendimento do público acadêmico.

Apesar de a Odontologia ser uma especialidade médica existente há anos, a contribuição das suas pesquisas para a saúde da população é ainda pouco 
conhecida não pelo desinteresse das pessoas, mas por falta de informação e de divulgação por parte dos próprios profissionais que atuam na área. No caso específico da Rede SIEO, a investigação foi conduzida no sentido de responder como aproveitar o potencial informacional existente em uma rede, a exemplo da SIEO, para ações de divulgação científica. Buscamos também esclarecer sobre estratégias organizacionais a serem empreendidas para viabilizar a participação da rede SIEO na popularização da Ciência.

O desenvolvimento da estrutura organizacional em rede vem se tornando uma opção real e ao mesmo tempo complexa que privilegia relações de interdependência das diversas organizações que constituem uma rede. O conhecimento sobre ela ainda está em construção, o que significa que mereceria ser melhor explorada, analisada e compreendida.

Por sua vez, a universidade como centro de produção sistematizada do conhecimento, necessita canalizar suas potencialidades no sentido da prestação de serviços a comunidade. Isto se torna possível mediante a comunicação e a viabilização de um processo de divulgação científica que possibilitaria ampliação do relacionamento entre universidade e seus diversos públicos. Daí a importância de um sistema planejado de comunicação para difundir de forma eficiente e eficaz a sua produção científica e com isso difundir seu conhecimento numa linguagem comum para todos os segmentos da sociedade civil.

A participação de bibliotecas universitárias em redes sociais possibilita a cooperação, a formação de parcerias e a adoção de padrões de comunicação que estimulam e impulsionam o compartilhamento, facilitando o atendimento mais adequado e efetivo das necessidades de informação de uma determinada comunidade, o que seria impossível para uma única instituição.

O panorama da literatura apresentado e, principalmente, a pesquisa de campo, mostraram que uma área especificamente dedicada ao conhecimento pode ajudar, porém, fundamental mesmo é a existência de núcleos estratégicos formados por membros de diferentes instituições, o que consiste em interações ou relacionamentos entre colaboradores independentes que operam simultaneamente para o alcance de um objetivo. O desenvolvimento das atividades dessas equipes não vem a garantir que todas as necessidades da instituição sejam contempladas, mas reduz de maneira significativa a possibilidade de algum aspecto importante não ser considerado ou algum serviço ser esquecido. 
A pesquisa mostrou também que os lideres exercem papel vital na instituição que depende do conhecimento. Compete a eles o incentivo ao desenvolvimento de ambiente, cultura e valores que fortalecem a sinergia, a aprendizagem e o compartilhamento do conhecimento ajustado à comunicação eficaz dos objetivos e estratégias da instituição, visando diminuir tempo e distância na comunicação de resultados de pesquisa.

De acordo com a literatura, a estrutura organizacional em rede se ergue sobre dois prismas: o da configuração da estrutura com base em atividades distribuídas e especializadas e um conjunto de relacionamentos mais fundamentados na dependência mútua do que na independência ou dependência para o alcance de um objetivo. Sua principal característica é que ela é uma estrutura aberta, em constante expansão, o que se dá pela integração de novos nós, desde que compartilhem os mesmos códigos, como por exemplo, um conjunto de valores ou um objetivo.

A Rede SIEO constitui-se em exemplo emblemático neste sentido. Resultados dos relatórios e documentos oficiais da Rede mostram que os objetivos de compartilhamento e disseminação da informação científica têm sido atingidos, com recursos adicionais para dotação de orçamentos para desenvolvimento de acervos e infraestrutura de informática, complementada por programas de capacitação de equipes no que tange à adoção de metodologias comuns de organização e tratamento de informações, quanto na utilização de aplicativos utilizados para realização de tarefas em rede.

No que se refere à divulgação científica, partiu-se do pressuposto de que a Rede SIEO poderia atuar além da atividade de apoio ao ensino, pesquisa e extensão, com uma ação mais criativa na divulgação dos conhecimentos gerados em suas instituições, contribuindo para apoio a ações educativas para além do ensino universitário.

Neste ponto, a relação com a atividade de extensão universitária não pode ser desprezada. Como visto anteriormente, a atividade de extensão se transforma em prática acadêmica que interliga a universidade, nas suas atividades de ensino e pesquisa, com as demandas da maioria da população, deixando de ser entendida apenas como prestação de serviço pontual, mas voltada para uma perspectiva social da educação para a cidadania, que, além da formação científica e tecnológica, preocupa-se com a formação humana em todas as suas dimensões. 
No entanto, não foi possível detectar participação das bibliotecas no apoio a atividades consideradas de extensão. Esse é o desafio a ser enfrentado pelo SIEO na popularização da ciência, para garantir sua atuação social, de modo que os conhecimentos presentes em seus acervos possam ser socializados para apropriação por outros públicos não científicos, tarefa que vai muito além da comunicação formal e burocrática da existência desses acervos.

No que se refere à perspectiva informacional, foi possível identificar práticas nas instituições que buscam a transmissão do conhecimento em uma determinada direção e que estão comumente associadas aos meios de comunicação como instrumentos utilizados para operacionalizar a disseminação da informação via programas de radio e TV, palestras e seminários empreendidos por pesquisadores universitários e não necessariamente pelas equipes das bibliotecas. Em relação às atividades dialogais presenciais, vemos que elas aparecem também associadas na maioria dos casos, à participação de equipes da unidade de ensino e pesquisa em feiras, exposições e eventos em geral, sem uma definição clara da participação das bibliotecas nessas ações, seja como apoio na produção de material, seja com uma atuação mais efetiva na elaboração de material em linguagem mais apropriada para este tipo de público.

Outras ações empreendidas pelas instituições se referem à atuação em programas assistenciais de saúde bucal em postos de saúde, escolas públicas e privadas, creches, grupos especiais, comunidades de bairro, mas ainda desenvolvidas de forma pontual, como laboratório de formação de profissionais.

No que se refere às necessidades para implementação ou desenvolvimento de atividades de popularização da ciência, as respostas confirmam dois problemas estruturais relativos às precárias condições de transporte e de recursos financeiros para atividades de extensão voltadas a programas de saúde bucal, o que leva a identificar a preocupação com o atendimento prioritário da saúde bucal da população neste momento e não necessariamente com programas de divulgação científica com o intuito de dar conhecimento dos resultados alcançados pelas recentes pesquisas e pela preocupação na formação educativa sobre as conseqüências para o cidadão do desenvolvimento científico e tecnológico.

A única sugestão, considerada essencial para um programa efetivo de Popularização da Ciência foi a de desenvolvimento de materiais didáticos mais 
Lúcia Maria S. V. Costa Ramos; Asa Fujino

Redes de informação científica e os desafios para popularização da ciência: estudo de caso na rede Sieo - sistema de informação especializado na área de odontologia

apropriados para divulgação em veículos também mais adequados para o público em geral, tais como revistas populares.

Por outro lado, as respostas abertas também mostram a existência de grupos preocupados com a necessidade de maior comprometimento do corpo docente com as ações relativas à extensão e divulgação científica, com a interligação maior entre os programas de pós-graduação e graduação que propiciariam contribuição imediata dos resultados de pesquisa na formação dos novos profissionais, e com 0 estabelecimento de calendários fixos para ações de divulgação externa.

Os resultados parciais, considerando análise comparativa entre questionários respondidos por bibliotecários, diretores das bibliotecas, e aqueles respondidos por docentes, diretores de setores das unidades de ensino e pesquisa, em posição hierárquica superior às bibliotecas, permitem concluir que:

a) no que pese o envolvimento das bibliotecas na consolidação da rede SIEO, entre os 8 (oito) bibliotecários que responderam o questionário, apenas dois manifestaram preocupação com ações visando à participação em programas de divulgação científica e, apenas um, com ações de popularização da ciência. A devolução de três questionários em branco ou sem respostas para a maioria das perguntas e, principalmente, as abertas, evidencia a dificuldade de respondentes no posicionamento sobre o assunto ou ainda a não preocupação com o assunto no momento.

b) no caso dos questionários respondidos por docentes ocupantes de cargos na hierarquia superior da unidade de ensino e pesquisa, foi possível constatar a preocupação maior com ações de extensão universitária e o cumprimento do seu papel junto à sociedade no que tange ao atendimento a programas de assistência à saúde bucal, embora manifestem consciência da responsabilidade social com aspectos educacionais inclusivos da população no que se refere às possibilidades de ações de popularização da ciência.

De modo geral, é possível afirmar que, embora as instituições universitárias tenham compromissos com a atividade de extensão, tais atividades ainda são tímidas se consideradas do ponto de vista das alternativas existentes no âmbito acadêmico, via programas de cooperação ou convênios com órgãos públicos e privados.

No entanto, assim como na maioria das bibliotecas universitárias, as integrantes da Rede SIEO têm forte atuação no apoio à pesquisa e ensino, via 
Lúcia Maria S. V. Costa Ramos; Asa Fujino

Redes de informação científica e os desafios para popularização da ciência: estudo de caso na rede Sieo - sistema de informação especializado na área de odontologia

organização e tratamento da informação científica, mas não foi possível identificar ações de apoio às atividades de extensão ou de divulgação científica com o intuito de viabilizar a popularização da ciência.

Assim, embora a Rede esteja preparada, do ponto de vista da estrutura organizacional e operacional em rede e da qualidade dos seus acervos, a carência de recursos financeiros e de equipe qualificada para geração de materiais específicos para divulgação científica e ações em prol da popularização da ciência inibe as possibilidades de aproveitamento imediato deste potencial.

Do ponto de vista da cultura organizacional, identificada por valores e símbolos presentes nos documentos e políticas de ação, é explícita a cultura acadêmica voltada para estímulo à pesquisa nas bibliotecas, como esperado em instituições universitárias, mas ainda pouco flexível à interação com segmentos mais populares da sociedade que demandariam ações de mediação no atendimento a este usuário, seja por intermédio de linguagens de recuperação da informação que permitissem estabelecer equivalências com a linguagem comum, seja por intermédio de apoio na representação de informações científicas em formas mais adequadas à divulgação científica.

Caberia ao Centro Coordenador da Rede elaborar um programa de discussão e capacitação de equipes para tais atividades. Tal programa poderia ser planejado e desenvolvido em conjunto com as equipes de docentes e discentes de graduação e pós-graduação, buscando o empenho na criação de um ambiente de equidade social, via ações para emergência de uma consciência pública sobre o valor da ciência, tais como:

- desenvolvimento de atividades de extensão à comunidade fornecendo informações com esclarecimentos sobre saúde e higiene bucal;

- elaboração de um plano de ação que possibilite acesso da população as informações sobre saúde bucal; via jornais e revistas pedagogicamente adequadas no conteúdo e linguagem. 


\section{REFERÊNCIAS}

BARNATT, Christopher. Cyber business: mindsets for a wired age. Great Britain: J. Wiley \& Sons, 1996.

BENJAMIN, Robert I.; LEVINSON, Eliot. A framework for managing it-enabled change. Sloan Management Review, Cambridge, v. 34, n. 4, p. 23, 1993.

BRASIL. Ministério da Ciência e Tecnologia. Livro branco: ciência, tecnologia inovação. Brasília: CT Brasil, 2002.

BRASIL. Ministério da Ciência e Tecnologia. Plano estratégico. No ar desde 2003a. Disponível em: <www.mct.gov.br>. Acesso em: 3 jun. 2011.

BRASIL. Ministério da Ciência e Tecnologia. Plano Plurianual 2004-2007. No ar desde 2003b. Disponível em: <www.mct.gov.br>. Acesso em: 3 jun. 2011.

CARVALHO, Telma; RAMOS, Lucia Maria Sebastiana Veronica Costa.

Representação das redes sociais e colaborativas do sistema de informação especializado na área de odontologia (SIEO). In: POBLACIÓN, Dinah; MUGNANINI, Rogerio (Org.). Redes sociais e colaborativas em informação científica. São Paulo: Angellara, 2009. p. 379-399.

CASTELLS, Manuel. Hacia el estado red?. Globalizacion economica e instituciones politicas en la era de la información. In: SEMINÁRIO INTERNACIONAL SOCIEDADE E A REFORMA DO ESTADO, 1998, São Paulo. Anais... São Paulo: [S.n.], 1998. 1$16 \mathrm{p}$.

COHEN, Aaron. The relationship between commitment forms and work outcomes: a comparison of three models. Human Relations, New York, v. 53, n. 3, p. 387-417, 2000.

CONSELHO NACIONAL DE DESENVOLVIVMENTO CIENTÍFICO E TECNOLÓGICO. CNPq. Edital MCT/CNPq no 12/2006: seleção pública de projetos para apoio a projetos de difusão e popularização da ciência e tecnologia. 2006.

Disponível em: <http://www.cnpq.br/editais/ct/2006/docs/012.pdf>. Acesso em: 3 jun. 2011.

FUJINO, Asa; STAL, Eva. Gestão da propriedade intelectual na universidade pública brasileira: diretrizes para licenciamento e comercialização. In: SIMPÓSIO DE GESTÃO DA INOVAÇÃO TECNOLÓGICA, 23., 2004, Curitiba. Anais... São Paulo: FEA/USP, 2004. 1 CD-ROM.

GHOSHAL, Sumantra; BARTLETT, Christopher A. A organização individualizada: as melhores empresas são definidas por propósitos, processos e pessoas. Rio de Janeiro: Campus, 2000.

GIL, Antonio Carlos. Como elaborar projetos de pesquisa. São Paulo: Atlas, 1988. 
GUARÁ, Isa Maria F. Rosa. Ciência, educação e inclusão social. In: MATOS, Caue (Org.). Ciência e inclusão social. São Paulo: Terceira Margem, 2002. p. 83-90.

KATAOKA, J. A disciplina das equipes. HSM Management, São Paulo, v. 3, n. 17, p. 56-60, nov. 1999.

KRZYZANOWSKI, Rosaly Favero. Implementação de rede de informação na área odontológica. São Paulo, 1990. (Projeto apresentado à W. K. Kellogg Foundation em parceria com a BIREME - Centro Latino-Americano e do Caribe em Ciências da Saúde).

LÉVY-LEBLOND, Jean Marc. About misunderstandings about misunderstandings. Public Understanding of Science, London, v. 1, n. 1, p. 17-21, 1992.

. Cultura científica: impossível e necessária. In: VOGT, C. (Ed.). Cultura científica: desafios. São Paulo: EDUSP/FAPESP, 2006. p. 28-43.

MACEDO, Monica Gonçalves. Do texto ao hipertexto: argumentação e legibilidade nos discursos da divulgação científica. 2002. 263 f. Tese (Doutorado em Comunicação) - Universidade Metodista de São Paulo, São Paulo, 2002.

MOREIRA, Ildeu de Castro. A inclusão social e a popularização da ciência e tecnologia no Brasil. Inclusão Social, Brasília, v. 1, n. 2, p. 11-16, abr./set. 2006.

MOREIRA, Ildeu de Castro; MASSARANI, Luisa. Aspectos históricos da divulgação científica no Brasil. In: MASSARANI, Luisa; MOREIRA, Ildeu de Castro; BRITO, Fatima (Org.). Ciência e público: caminhos da divulgação científica no Brasil. Rio de Janeiro: Casa da Ciência, 2002. p. 43-64.

MYERS, Greg. Discourse studies of scientific popularization: questioning the boudaries. Discourse Studies, Abingdon, v. 5, n. 2, p. 265-279, 2003.

NIETO, Maurício. El público y las políticas de ciência y tecnología. Interciencia, Venezuela, v. 27, n. 2, p. 80-83, 2002.

NOHRIA, Nitin; ECCLES, Robert. (Coord.). Netwooks and organizations: structure, form and action. Boston: Harvard Business School Press, 1992.

OLIVARES, José Enrique Louffat. Análise da estrutura organizacional em Rede e suas negociações no contexto de alianças estratégicas. 2003. 215 f. Tese (Doutorado em Administração) - Faculdade de Economia e Administração, Universidade de São Paulo, São Paulo, 2003.

$\mathrm{PECl}$, Alketa. Emergência e proliferação de redes organizacionais: marcando mudanças no mundo de negócios. In: ENCONTRO DA ASSOCIAÇÃO NACIONAL DOS PROGRAMAS DE PÓS-GRADUAÇÃO EM ADMINISTRAÇÃO - ENANPAD, 22., 1998, Foz de lguaçu, PR. Anais... Foz de Iguaçu, PR: ANPAD, 1998. 1 CD-ROM. 


\section{Title}

Networks of scientific information and the Challenges for science popularization: case study in SIEO Network - Specialized Information System in Dentistry Area

\section{Abstract}

Introduction: Contemporary studies about science have highlighted the deep social roots that both knowledge and scientific practices have. At the same time, arises the awareness that the popularization of science is fundamental to scientific knowledge, may become an essential component of the culture of the citizens in general, providing the integration cultural, social and economic.

Objective: To study the potential role of cooperative networks of information in the popularization of science, considering several organizational challenges (infrastructure, human resources, senior management commitment) that a SIEO network would have to operate in this new context.

Methodology: It is based on an exploratory study guided the model of collaborative network of information that used a qualitative research as guide as well as a documentary research combined with a case study.

Results: Results show that, although the network is prepared in terms of organizational and operational structure and quality of their collections, the lack of financial resources and qualified staff for the generation of specific materials to disseminate scientific and actions towards the popularization of science inhibits the possibilities of immediate use of this potential. It also showed that organizational culture is still somewhat flexible to the interaction with the most popular segments of society.

Conclusions: Concludes that the fact cited, demands actions of mediation in service to this user, whether by language of information retrieval which allow establish equivalences between specialized language and ordinary language, whether other more appropriate forms of representation of scientific information, aimed at scientific dissemination.

Keywords: Network for Scientific Information. Planning and management services. Popularization of Science. Scientific dissemination. Organizational Structure.

\section{Titulo}

Redes de información científica y los desafíos de la popularización de la ciencia: un estudio de caso en la red SIEO - Sistema de Información Especializada en el área de la Odontología.

\section{Resumen}

Introducción: Los estudios contemporáneos sobre ciencia evidencian las profundas raíces sociales que el conocimiento y las prácticas científicas poseen. Juntamente surge la consciencia de que la popularización de la ciencia es fundamental para el conocimiento de los ciudadanos en general, posibilitando la integración cultural, social y económica.

Objetivo: Estudiar el potencial de actuación de las redes cooperativas de información en la popularización de la ciencia, considerando los desafíos organizacionales (infraestructura, 
Lúcia Maria S. V. Costa Ramos; Asa Fujino

Redes de informação científica e os desafios para popularização da ciência: estudo de caso na rede Sieo - sistema de informação especializado na área de odontologia

recursos humanos, comprometimiento de la alta administración) que una red como la SIEO tendría para actuar en ese nuevo contexto.

Metodología: Se trata de un estudio exploratorio basado en el modelo de red colaborativa de información que utiliza la investigación cualitativa como marco de orientación para la investigación empírica y se junta a la investigación documental con el estudio de caso.

Resultados: Muestran que, aunque la Red esté preparada desde el punto de vista de la estructura organizacional y operacional y de la calidad dos sus acervos, la necesidad de recursos financieros y de equipe calificada para la generación de materiales específicos para divulgación científica y acciones a favor de la popularización de la ciencia inhibe las posibilidades de la utilización inmediata de este potencial. También muestra que la cultura organizacional es todavía poco flexible a la interacción con segmentos más populares de la sociedad.

Conclusiones: Se concluye que tal hecho demanda acciones de mediación en el atendimiento de este usuario, sea por lenguaje de recuperación de la información que posibilitan establecer equivalencias entre la lengua de la especialidad y el lenguaje común, sea por formas más adecuadas de representación de la información científica, visando la divulgación científica.

Palabras clave: Red de Información Científica. Planificación y gestión de servicios. Popularización de la Ciencia. Ciencias de la Comunicación. Estructura Organizativa.

Recebido em: 17.04 .2012

Aceito em: 10.05.2013 